\title{
The Effect of Use of Platelet Rich Plasma (PRP) on Venous Ulcer Size in Comparison to the Usual Method of Dressing and Compression Bandage
}

\author{
Mohamed Abd El-Monem Abd El-Salam Rizk, MD; Wafi Fouad Salib, MD; Ramy Mikhael \\ Nageeb, MD \\ Vascular Surgery Department, General Surgery Department, Ain Shams University
}

\begin{abstract}
Aim: To compare the clinical efficacy of platelet rich plasma in the management of chronic venous ulcers (as regards the time of complete ulcer healing or shrinkage in size) with the conventional methods of treatment of venous ulcers (compression and dressing alone).
\end{abstract}

Patients \& methods: A case control study was conducted over 40 patients having lower limb chronic venous ulcers, attending the outpatient clinic of vascular surgery, Ain Shams university hospitals in the period from July 2013 till January 2015. Twenty patients with chronic venous ulcers (cases) were treated with platelet rich plasma - topically applied to the ulcer then dressed by vasline gauze and compressed by graduated elastic stocking - for 6 sessions with one week interval between sessions. The second group (control) included the other 20 patients who were managed conservatively by compression using graduated elastic stockings below the knee and dressing using saline and vasline guaze weekly for 6 weeks.

Results: We noticed that the percentage of change in size, length and width of the ulcer after the end of treatment showed highly statistically significant difference between cases and controls after 6 weeks of treatment, where complete healing and shrinkage in size of the ulcer were more obvious in cases treated with PRP than those who were treated only by the conservative method, who showed mild improvement after 6 weeks of conservative treatment. 35\% of patients in cases group achieved complete healing compared to $0 \%$ of patients in control group.

Conclusion: Platelet rich plasma shows promise as an effective treatment modality in the setting of chronic venous leg ulcers. It was found to be effective in enhancing wound healing in chronic venous leg ulcers when compared to conventional methods of treatment (compression + dressing), as regards length, width and size of the ulcer and treatment outcome.

Key words: Venous ulcer, platelet rich plasma, PRP.

\begin{abstract}
Introduction
Venous ulcers are wounds that are thought to occur due to improper functioning of venous valves, usually of the legs. ${ }^{1}$
\end{abstract}

They are the most severe and debilitating sequel of chronic venous insufficiency (CVI) and venous hypertension. They account for nearly $80 \%$ of all lower extremity ulcers, with an overall prevalence of approximately $1-2 \% .^{2}$

Conventional therapies such as dressings, surgical debridement, compression bandage and even skin grafting cannot provide satisfactory healing since these treatments are not able to provide necessary growth factors that can modulate healing processes. ${ }^{3}$

The use of platelet-rich plasma (PRP) and plasma rich in growth factors (PRGF) is a relatively new approach considered clinically useful in various fields of medicine (ie, traumatology, cosmetic surgery, ophthalmology, and dermatology). ${ }^{4-6}$

Platelet-rich plasma (PRP) contains a high concentration of thrombocytes and the granules of platelets contain platelet-released growth factors that include molecules such as platelet-derived growth factor (PDGF), vascular endothelial growth factor (VEGF), and transforming growth factor, that trigger biological effects including directed cell migration (ie, chemotaxis), angiogenesis, and cell proliferation and differentiation, which are key in the processes of tissue repair and regeneration. ${ }^{7}$

Topical application of growth factors stimulates the rejuvenation of photo-aged facial skin, improving its clinical appearance and inducing new collagen synthesis. Since platelet rich plasma secretes various growth factors with roles in skin regeneration, it may be hypothesized that it may induce the synthesis of collagen and other matrix components by stimulating the activation of fibroblasts, thus, rejuvenating the skin. ${ }^{8}$ 


\section{Patients and methods}

Patients with chronic venous ulcers who attended the outpatient clinic of vascular surgery in Ain Shams University hospitals were enrolled in the study.

The study was conducted on 40 patients in the period from July 2013 till January 2015 who fulfilled the following criteria:

1. Patients' age from $14-65$ years.

2. Patients with venous ulcers for more than 6 months duration who haven't received any treatment before.

3. Patients who had previous history of DVT or underwent ligation of saphenofemoral junction and stripping of great saphenous vein for incompetent saphenofemoral junction.

\section{We excluded patients having the following criteria from our study:}

1. Patients with chronic medical disease affecting healing of wounds as chronic liver disease, chronic renal failure or uncontrolled diabetes mellitus.

2. Patients with infected ulcers.

3. Patients having peripheral arterial disease.

4. Patients with incompetent saphenofemral junction for surgical intervention.

\section{Methods:}

\section{All patients were subjected to:}

\section{Careful history taking with emphasis on:}

1. The presence of chronic disease like Diabetes Mellitus.

2. Occupation and family history of varicose veins or DVT.

3. The onset, course and duration of venous ulcer.

4. Associated pain.

5. History of possible etiology either varicose veins to which surgical intervention was done, or history of previous DVT.

Thorough clinical examination as regards:

1. Ulcer: size, length and width.

2. Examination of lower limb venous system bilaterally.

3. Complete pulse examination performed to exclude underlying peripheral arterial disease.
4. Signs of deep venous thrombosis to differentiate between primary and secondary venous ulcer.

Duplex scanning: commenting on the superficial and deep system, saphenofemoral junction competence, saphenopopliteal junction competence and perforators.

\section{Procedure:}

After that the patients were given numbers by random-number generator and divided into two groups:

Group (A) (case): Patients with odd numbers were included, 20 patients with chronic venous ulcer who were treated with platelet rich plasma for 6 sessions with one week interval between sessions, together with graduated elastic stocking.

Group (B) (control): Patients with even numbers were included, 20 patients with chronic venous ulcer who were managed conservatively by compression using graduated elastic stockings below the knee and dressing using saline and Vaseline gauze weekly for 6 weeks.

\section{Patients in group (A) (case) were subjected to the following:}

1. Complete blood picture and porthrombin time to detect any coagulation defect or bleeding tendency.

2. After approval of the patients and after full explanation about the new procedure, they were treated by platelet rich plasma in 6 separate sessions as once weekly.

3. Every week the ulcer area and volume were calculated and photographs were taken by a digital camera (16 megapexils), wound area was calculated using the formula for an ellipse: Length $\times$ width $\times 0.7854$ (an ellipse is closer to a wound shape than a square or rectangle that would be described by simple length $x$ width), ${ }^{9}$ the use of an ellipse for calculating wound measurement has been used in a database of more than 120,000 wounds and in randomized controlled trials in wound healing literature. ${ }^{10}$

4. Steps of PRP preparation can be illustrated as following:

- $10 \mathrm{ml}$ of venous blood was withdrawn from the patient and put in 2 tubes containing Ethylene Diamine Tetraacetic Acid (EDETA) As an anticoagulant. 

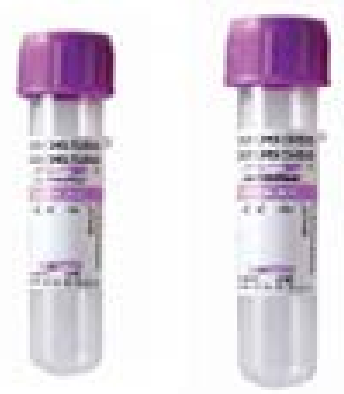

Fig 1: Ethylene Diamine Tetraacetic Acid (EDETA) tubes.

- First centrifugation was done using a laboratorial centrifuge (Beckman J-6M Induction Drive Centrifuge, Beckman Instruments Inc., Palo Alto, CA, EUA) with the speed of 1500 Round Per Minute (RPM) for 10 minutes at room temperature. This led to the separation of the sample to 3 layers from above downwards: The plasma layer then the buffy coat layer then RBCS layer.

- $\quad$ The plasma and buffy coat were pipetted and transferred to other $5 \mathrm{ml}$ vacuum tube then the sample was exposed to a new centrifugation cycle with the speed of 1500 RPM for 5 minutes, this led to the separation of 2 layers: above platelet poor plasma and below platelet rich plasma.

- $\quad$ The platelet rich plasma layer was separated and then activated by adding $0.1 \mathrm{ml} \mathrm{Ca}$ gluconate to each $1 \mathrm{ml}$ PRP in a Petri dish and kept in an incubator with temperature of 37 degree until forming a gel layer; then it was ready for use.

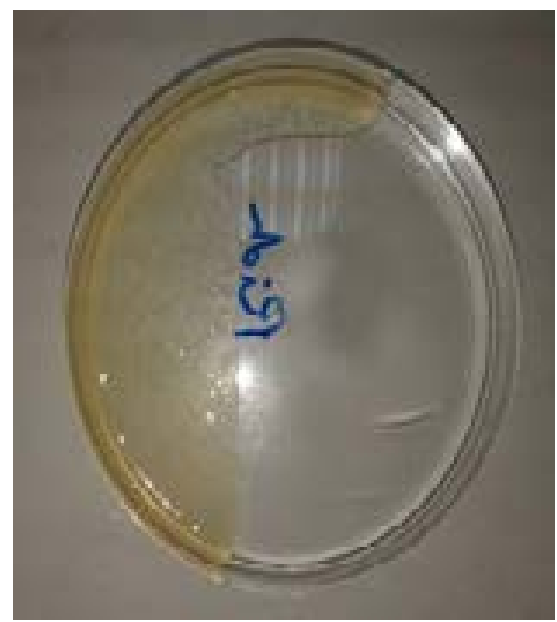

Fig 2: The gel form of PRP in the petri dish.

5. The ulcer was exposed to proper debridement for any necrotic tissue and irrigated by saline till it became clean and ready to receive the gel layer of PRP.
6. PRP was then applied to the ulcer and covered with Vaseline gauze and sterile dressing.

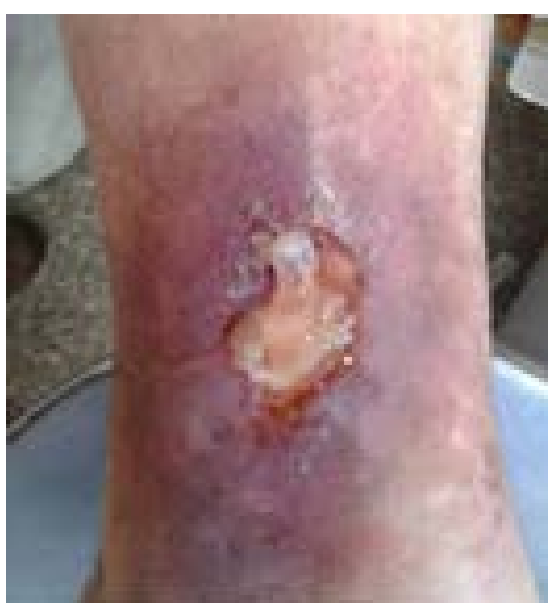

Fig 3: The PRP gel applied on the ulcer.

7. At the end of the session the patient was advised to wear elastic stocking (below knee, class II compression); and to keep the dressing containing the PRP gel on the ulcer for 3 days; and the session was repeated for 6 times.

\section{Patients in group (B) (control) were managed conservatively as follow:}

1. Instruction about limb elevation.

2. Dressing using simple non-adherent dressing (Vaseline gauze) after proper cleaning of ulcer area using normal saline.

3. Compression using elastic stocking.

4. They also were followed up by 6 visits one week apart and ulcer area and volume were calculated as patients in group $A$.

Then patients in the 2 groups were compared as regard the response to the management plan which was assessed by reduction in the size of ulcer area and improvement of symptoms.

\section{Results}

This study was conducted on 40 patients from July 2013 till January 2015. 
Table 1: Description of personal and medical data among both groups

\begin{tabular}{|c|c|c|c|c|c|c|c|}
\hline & & \multicolumn{4}{|c|}{ Group } & \multirow[b]{2}{*}{ P-value } & \multirow[b]{2}{*}{ Significance } \\
\hline & & \multicolumn{2}{|c|}{$\begin{array}{c}\text { Case } \\
\text { Group (A) }\end{array}$} & \multicolumn{2}{|c|}{$\begin{array}{c}\text { Control } \\
\text { Group (B) }\end{array}$} & & \\
\hline \multicolumn{2}{|c|}{$\begin{array}{c}\text { Age (year) } \\
\text { Mean ( }(\mathrm{SD})\end{array}$} & \multicolumn{2}{|c|}{$\begin{array}{c}20-59 \\
36.35( \pm 10.25)\end{array}$} & \multicolumn{2}{|c|}{$\begin{array}{c}20-42 \\
32.45( \pm 7.49)\end{array}$} & $0.177 \neq$ & NS \\
\hline \multirow{2}{*}{ Sex } & Female $(n \%)$ & 1 & $5.0 \%$ & 0 & $0 \%$ & \multirow{2}{*}{$1.0 * *$} & \multirow{2}{*}{ NS } \\
\hline & Male $(n \%)$ & 19 & $95.0 \%$ & 20 & $100.0 \%$ & & \\
\hline \multirow{2}{*}{ Smoking } & $\begin{array}{l}\text { Smoker } \\
(\mathrm{n} \%)\end{array}$ & 17 & $85.0 \%$ & 17 & $85.0 \%$ & \multirow{2}{*}{$1.0 * *$} & \multirow[b]{2}{*}{ NS } \\
\hline & $\begin{array}{c}\text { Non Smoker } \\
(\mathrm{n} \%)\end{array}$ & 3 & $15.0 \%$ & 3 & $15.0 \%$ & & \\
\hline \multirow{2}{*}{ Residence } & Urban (n\%) & 15 & $75.0 \%$ & 17 & $85.0 \%$ & \multirow{2}{*}{$0.695 * *$} & \multirow{2}{*}{ NS } \\
\hline & Rural (n\%) & 5 & $25.0 \%$ & 3 & $15.0 \%$ & & \\
\hline \multirow{2}{*}{$\begin{array}{l}\text { Occupation } \\
\text { with Long } \\
\text { standing }\end{array}$} & Yes (n\%) & 14 & $70 \%$ & 14 & $70 \%$ & \multirow{2}{*}{$1.0 *$} & \multirow[b]{2}{*}{ NS } \\
\hline & No (n\%) & 6 & $30 \%$ & 6 & $30 \%$ & & \\
\hline \multirow{2}{*}{ DM } & Yes (n\%) & 2 & $10.0 \%$ & 0 & $0 \%$ & \multirow{2}{*}{$0.487 * *$} & \multirow{2}{*}{ NS } \\
\hline & No (n\%) & 18 & $90.0 \%$ & 20 & $100.0 \%$ & & \\
\hline \multirow{2}{*}{ Hypertension } & Yes (n\%) & 0 & $0 \%$ & 0 & $0 \%$ & \multirow{2}{*}{---} & \multirow{2}{*}{--- } \\
\hline & No $(n \%)$ & 20 & $100.0 \%$ & 20 & $100.0 \%$ & & \\
\hline \multirow{2}{*}{$\begin{array}{l}\text { Cardiac } \\
\text { disease }\end{array}$} & Yes (n\%) & 0 & $0 \%$ & 0 & $0 \%$ & \multirow[t]{2}{*}{---} & \multirow{2}{*}{--- } \\
\hline & No (n\%) & 20 & $100.0 \%$ & 20 & $100.0 \%$ & & \\
\hline
\end{tabular}

FStudent $\mathrm{t}$ test $\quad *$ Chi-Square Tests $\quad * *$ Fisher exact test

As regards the etiology of the ulcer in both groups it was found that $15(75 \%)$ patients out of 20 patients in group (A) had previous history of DVT, while in group (B) there were $16(80 \%)$ patients out of 20 patients who had previous history of DVT. these results had a P value of 1.000 using Fisher's exact test which was a non significant statistical result between both groups.

As regards the size of the ulcer, the following table and figure showed no statistically significant difference between cases and controls groups as regard length and width of the ulcer as well as the formula of an ellipse before the start of treatment.

Table 2: Comparison between cases and controls groups as regard length, width and formula of ulcer before treatment

\begin{tabular}{|c|c|c|c|c|c|c|c|c|}
\hline & \multicolumn{6}{|c|}{ Group } & \multirow{3}{*}{ P* } & \multirow{3}{*}{ Sig } \\
\hline & \multicolumn{3}{|c|}{ Case } & \multicolumn{3}{|c|}{ Control } & & \\
\hline & Mean & \pm ISD & Median & Mean & $\mathbf{I S D}$ & Median & & \\
\hline Length of the ulcer at the start of treatment $(\mathrm{cm})$ & 3.28 & 2.81 & 2.4 & 2.30 & 0.21 & 2.4 & 0.556 & NS \\
\hline Width of the ulcer at the start of treatment $(\mathrm{cm})$ & 1.99 & 1.44 & 1.8 & 1.65 & 0.66 & 1.7 & 0.989 & NS \\
\hline Formula of an ellipse at the start of treatment & 7.97 & 16.89 & 3.0 & 2.95 & 1.23 & 3.0 & 0.560 & NS \\
\hline
\end{tabular}




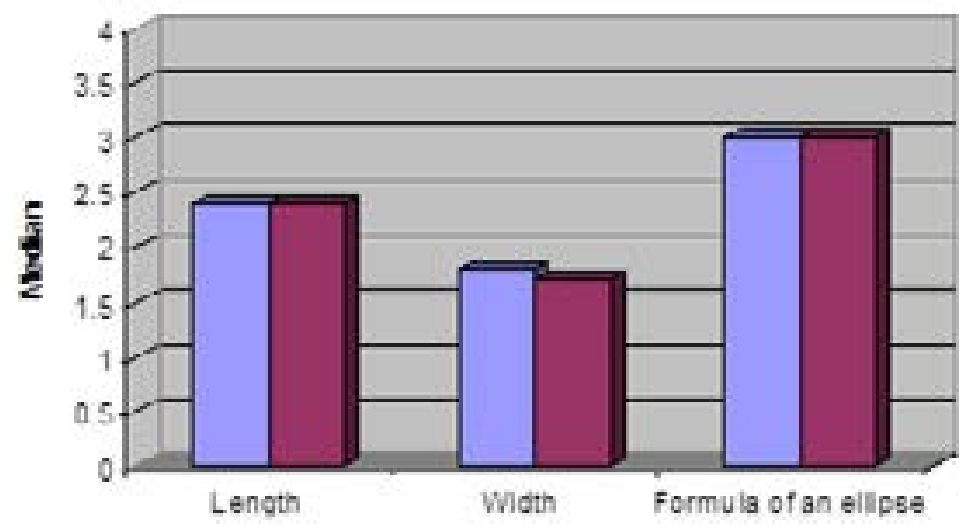

Before treatunent

a Case aContol

Fig 4: Comparison between cases and controls groups as regard length, width and formula of ulcer before treatment.

Table 3: Comparison between cases and controls groups as regard length, width and formula of ulcer after treatment

\begin{tabular}{|c|c|c|c|c|c|c|c|c|}
\hline & \multicolumn{6}{|c|}{ Group } & \multirow{3}{*}{ P* } & \multirow{3}{*}{ Sig } \\
\hline & \multicolumn{3}{|c|}{ Case } & \multicolumn{3}{|c|}{ Control } & & \\
\hline & Mean & \pm SD & Median & Mean & \pm SD & Median & & \\
\hline Length of the ulcer at the end of treatment $(\mathrm{cm})$ & 1.59 & 1.92 & 0.9 & 2.00 & 0.55 & 2.2 & 0.028 & S \\
\hline Width of the ulcer at the end of treatment $(\mathrm{cm})$ & 1.04 & 1.27 & 0.6 & 1.63 & 0.69 & 1.7 & 0.02 & S \\
\hline Formula of an ellipse at the end of treatment & 3.05 & 5.86 & 0.4 & 2.81 & 1.46 & 3.0 & 0.019 & S \\
\hline
\end{tabular}

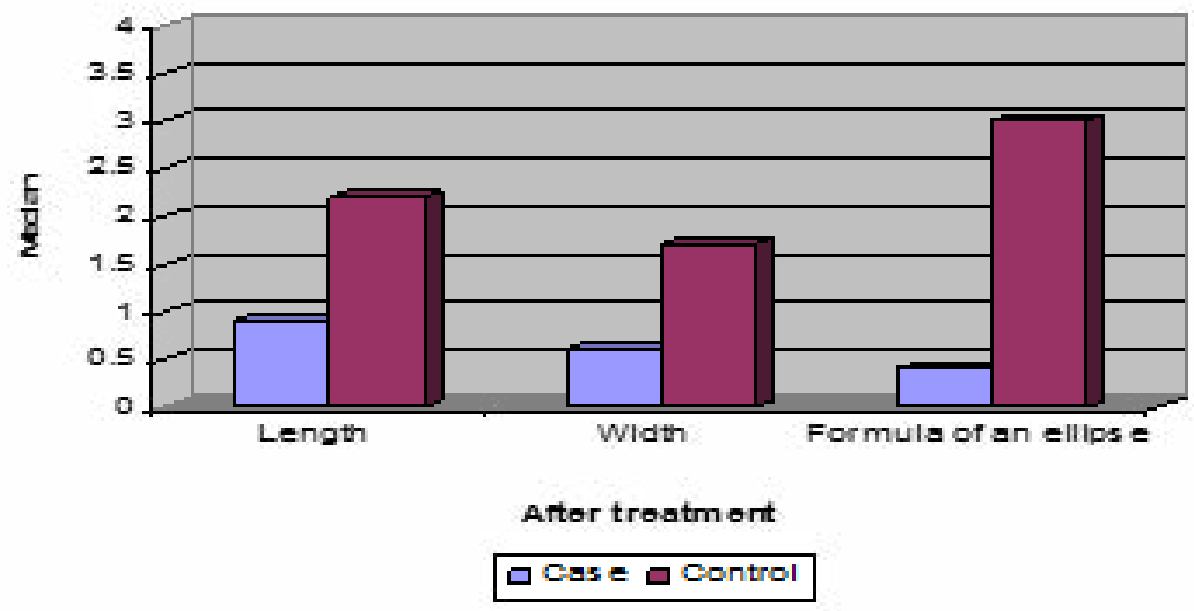

Fig 5: Comparison between cases and controls groups as regard length, width and formula of ulcer after treatment.

Here in this table we can see that there was a statistically significant difference between cases and controls groups as regards length and width of the ulcer as well as the formula of an ellipse at the end of treatment with $P$ value $<0.05$ which means that there was marked improvement in patients treated with PRP when compared to patients treated conservatively.

As for the change in the size of the ulcer before treatment and after treatment, the following table showed a comparison between the changes in size of the ulcer between cases and controls. 
Table 4: Comparison of the change in size of ulcers between both groups

\begin{tabular}{lcccccccc}
\hline & \multicolumn{3}{c}{ Group (A) Case } & \multicolumn{3}{c}{ Group (B) Control } & \\
\cline { 2 - 9 } & Mean & ISD & Median & Mean & ISD & Median & & \\
\hline Change in formula & 4.92 & 11.94 & 1.81 & 0.13 & 0.27 & 0 & 0.0001 & HS \\
Percent of change in formula & 67.61 & 36.66 & 74.38 & 13.67 & 28.06 & 0 & 0.0001 & HS \\
\hline
\end{tabular}

In this table we noticed that the percentage of change in formula of an ellipse of the ulcer after the end of treatment showed highly statistically significant difference between cases and controls with $\mathrm{P}$ value $<0.01$ adding more evidence to treatment efficacy of PRP when compared with the traditional methods.

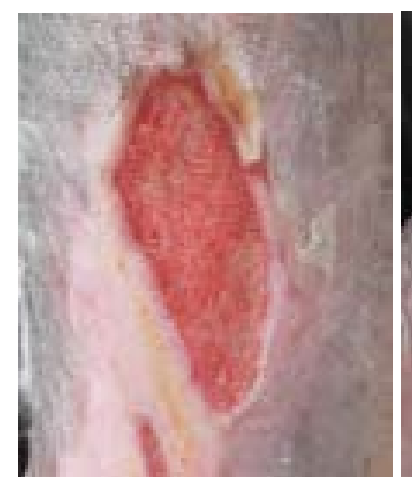

a

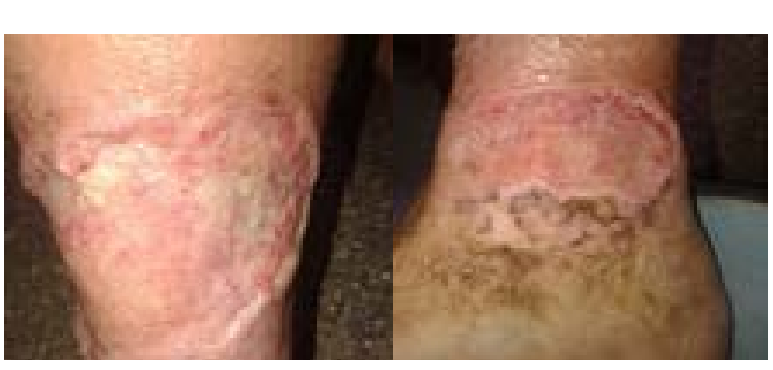

b Before

after 5 weaks

Fig 6: Two patients from group (A) with $>\mathbf{5 0} \%$ improvement in the size of the ulcer after 4 weeks in (a), and after 5 weeks in (b).

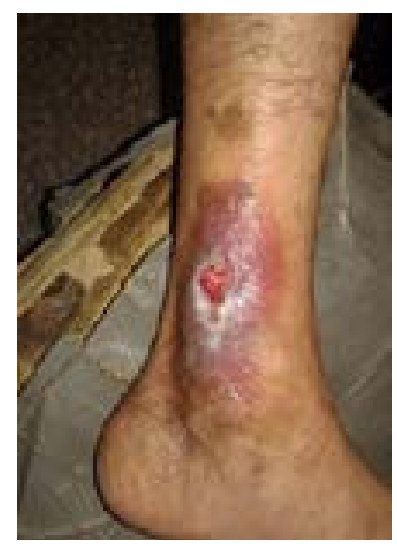

a

Before

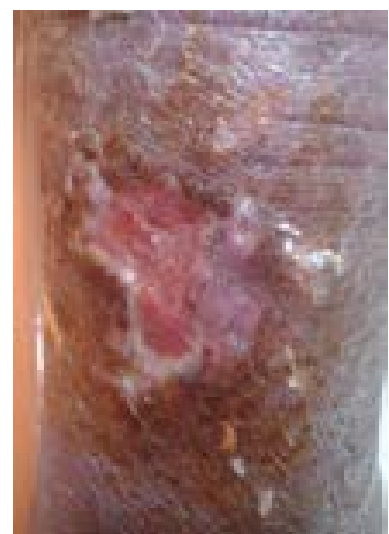

Before

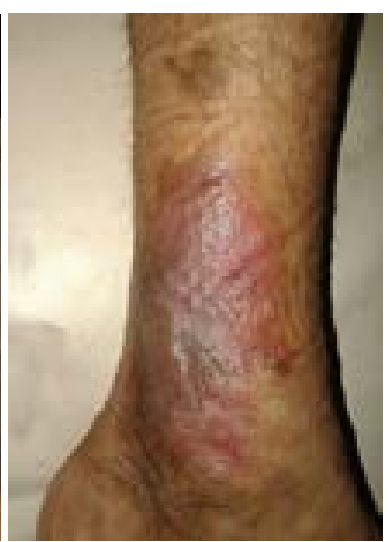

after

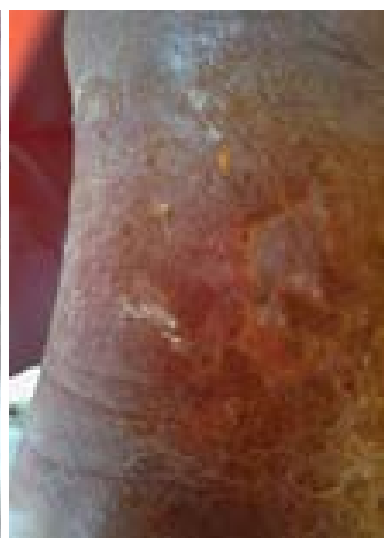

after

Fig 7: Two patients $(a, b)$ from group $(A)$ with complete healing of the ulcer after 6 weeks.

As for the overall results between both groups as regard complete healing of the ulcers or improvement or no improvement, it's shown in the following table.

Table 5: Comparison of the change in size of ulcers between both groups

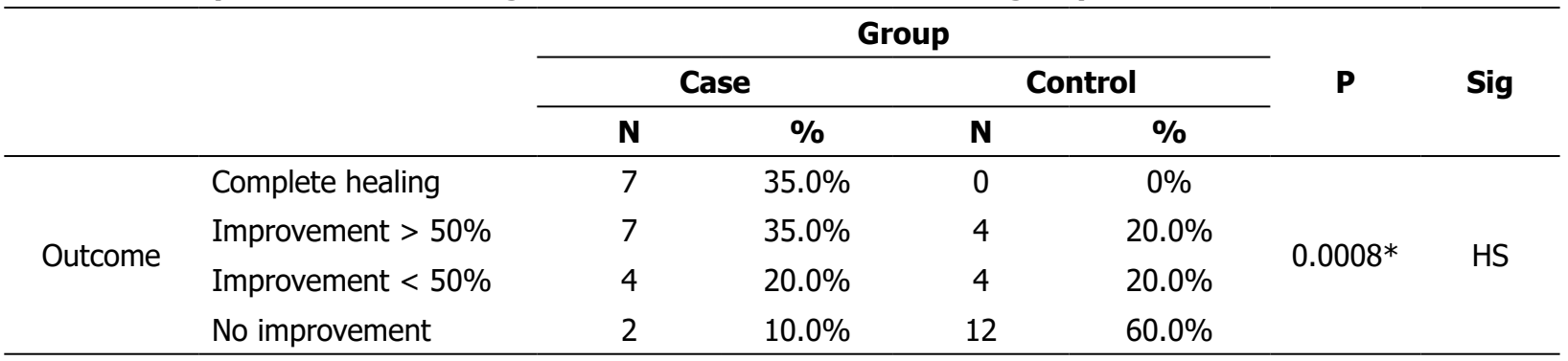




\section{Discussion}

Platelet-rich plasma (PRP) is a volume of autologous plasma that has a platelet concentration above baseline. ${ }^{11}$ Its use in medicine is based on the fact that platelets contain many growth factors in their alpha granules. These factors have a wellknown role in the process of tissue repair. Thus, the concentration of these substances in injured tissues could be beneficial to providing more agility to the regeneration processes. ${ }^{9}$

Platelet-rich plasma enhances wound healing by promoting the healing process by seven growth factors present in it. They are platelet derived growth factor ( $a a, a \beta, a \beta)$, fibroblast growth factor, vascular endothelial growth factor, epidermal growth factor and transforming growth factor. These growth factors are important in modulating mesenchymal cell recruitment, proliferation and extra cellular matrix synthesis during the healing process. $^{12}$

In our study complete healing of the ulcer occurred in $35 \%$ of the case study group and improvement of $>50 \%$ of the ulcer size occurred in another $35 \%$ of the study group who were treated using PRP in comparison to $0 \%$ complete healing in and $20 \%$ improvement of $>50 \%$ of the ulcer size in the control group.

Healing of chronic venous leg ulcers in response to PRP therapy was reported in a previous study conducted by Steenvoorde et al. on 12 patients with 13 wounds treated with PRP, showing that 7 of 13 wounds required more than 1 application to start improvement, with mean treatment period of 4.2 weeks. ${ }^{13}$

In agreement with our study, the results of a study by Frykberg et al, conducted on 49 patients with 65 non healing ulcers showed that 63 of 65 ulcers responded with reduction in area, volume and undermining of the ulcers in a mean of 2.8 weeks with PRP therapy. ${ }^{14}$ Wound area was calculated using the formula for an ellipse: (Length $\times$ width $\times$ 0.7854 ). Volume was calculated using the formula (length $\times$ width $\times 0.7854) \times$ depth. ${ }^{10}$

Kakudo et al. treated five cases of intractable skin ulcer (Full thickness skin or soft tissue defects resistant to conventional ointment treatment) with autologous PRP, among which three ulcers healed completely within 4 weeks and epithelization of wound occurred within 6.6 weeks in average. They reported no complications in any patient and all wounds achieved complete epithelialization. ${ }^{15}$

In a study by Suryanarayan et al. on 24 patients with 33 non healing ulcers treated with PRP at weekly intervals for a maximum of 6 treatments, they showed marked reduction in area and volume of the ulcers. The mean percentage of reduction was $91.7 \%$ and $95 \%$ respectively. ${ }^{16}$

\section{Conclusion}

Platelet rich plasma shows promise as an effective treatment modality in the setting of chronic venous leg ulcers. It was found to be effective in enhancing wound healing in chronic venous leg ulcers when compared to conventional methods of treatment (compression + dressing), as regards length, width and size of the ulcer and treatment outcome.

Conventional treatment showed mild improvement after the 6 sessions. PRP therapy for 6 weeks duration is sufficient to obtain significant effect. There is no standard method of preparation of PRP in literature but the device must use a double centrifugation technique.

The procedure can be easily adapted to most clinical settings with minimal infrastructure so that many patients can benefit from this cellular therapy. PRP is a safe, simple, inexpensive and biocompatible procedure without any adverse events.

\section{References}

1. Milic DJ, Zivic SS, Bogdanovic DC, Karanovic ND, Golubovic ZV: Risk factors related to the failure of venous leg ulcers to heal with compression treatment. J Vasc Surg 2009; 49: 1242-1247.

2. Evans $\mathrm{CJ}$, Fowkes $\mathrm{FG}$, Ruckley $\mathrm{CV}$, Lee $\mathrm{AJ}$ : Prevelance of varicose veins and chronic venous insufficiency in men and women in the general population. Edinburgh Vein Study. J Epidemiol Community Health 1999; 53: 149153.

3. Braund R, Hook S, Medlicott NJ: The role of topical growth factors in chronic wounds. Curr Drug Deliv 2007; 4: 195 - 204.

4. Alsousou J, Thompson M, Hulley $P$, Noble A, Willett K: The biology of platelet-rich plasma and its application in trauma and orthopaedic surgery: A review of the literature. $J$ Bone Joint Surg Br 2009; 91: 987-996.

5. Alio JL, Abad M, Artola A, Rodriguez-Prats JL, Pastor S, Ruiz-Colecha J: Use of autologous platelet-rich plasma in the treatment of dormant corneal ulcers. Ophthalmology 2007; 4: 1286-1293.

6. Man D, Plosker H, Winland-Brown JE: The use of autologous platelet-rich plasma (platelet 
gel) and autologous platelet poor plasma (fibrin glue) in cosmetic surgery. Plast Reconstr Surg 2001; 107: 229-237.

7. Lubkowska A, Dolegowska B, Banfi G: Growth factor content in PRP and their applicability in medicine. J Biol Regul Homeost Agents 2012; 26: 3S-22S.

8. Kim DH, Je YJ, Kim CD, Lee YH, Seo YJ, Lee JH, Lee Y: Can Platelet rich plasma be used for skin rejuvenation? Evaluation of effects of platelet rich plasma on human dermal fibroblast. Ann Dermatol 2011, 23: 424-431.

9. Sarvajnamurthy $S$, Suryanarayan $S$, Budamakuntala L, Suresh DH: Autologous platelet rich plasma in chronic venous ulcers: Study of 17 cases. J Cutan Aesthet Surg 2013; 6: 97-99.

10. Blume PA, Walters J, Payne W, Ayala J, Lantis J: Comparison of negative pressure wound therapy using vacuum assisted closure with advanced moist wound therapy in the treatment of diabetic foot ulcers: A multicenter randomized controlled trial. Diabetes Care, 2008; 31: 631636.

11. Marx RE. Platelet-rich plasma (PRP): What is PRP and what is not PRP? Implant Dent 2001; 10: 225-228.
12. Singh RP, Marwaha N, Malhotra P, Dash S: Quality assessment of platelet concentrates prepared by platelet rich plasma platelet concentrate, buffy coat poor platelet concentrate (BC PC) and apheresis PC methods. Asian J Transfus Sci 2009; 3: 86-94.

13. Steenvoorde $P$, van Doorn, LP, Naves, C, Oskam J: Use of autologous platelet-rich fibrin on hard-to-heal wounds. J Wound Care 2008; 17: 60-63.

14. Frykberg RG, Driver VR, Carman D, Lucero B, Borris-Hale C, Fylling CP, Rappl LM, Clausen PA: Chronic wounds treated with a physiologically relevant concentration of platelet-rich plasma gel: A prospective case series. Ostomy Wound Manage 2010; 56:36-44.

15. Kakudo N, Kushida S, Ogura, N, Hara T, Suzuki $\mathrm{K}$, Kusumoto K: The use of autologous platelet rich plasma in the treatment of intractable skin ulcer. Open J Reg Med 2012; 1: 29-32.

16. Suryanarayan S, Budamakuntla L, Khadri SI, Sarvajnamurthy S: Efficacy of autologous platelet-rich plasma in the treatment of chronic nonhealing leg ulcers. Plast Aesthet Res 2014; 1: 65-69. 